\title{
Do type 1 receptor tyrosine kinases inform treatment choice? A prospectively planned analysis of the TEAM trial
}

J M S Bartlett ${ }^{\star 1,2}$, C L Brookes ${ }^{3}$, T Piper $^{2}$, C J H van de Velde ${ }^{4}$, D Stocken ${ }^{3}, \mathrm{~N} \mathrm{Lyttle}^{1}$, A Hasenburg ${ }^{5}$, M A Quintayo ${ }^{1}$, D G Kieback ${ }^{6}$, H Putter ${ }^{4}$, C Markopoulos ${ }^{7}$, E M-K Kranenbarg ${ }^{4}$, E A Mallon ${ }^{8}$, L Y Dirix ${ }^{9}$, C Seynaeve ${ }^{10}$ and D W Rea ${ }^{2}$

${ }^{1}$ Transformative Pathology, Ontario Institute for Cancer Research, Toronto, Canada M5G OA3; ${ }^{2}$ Edinburgh Cancer Research Centre, University of Edinburgh, Edinburgh EH4 2XR, UK; ${ }^{3}$ Cancer Research UK Clinical Trials Unit, University of Birmingham, Birmingham B15 2TT, UK; ${ }^{4}$ Leiden University Medical Center, Leiden 2300 RC, The Netherlands; ${ }^{5}$ Department of Obstetrics, University Hospital, Freiburg D-79106, Germany; ${ }^{6}$ Department of Obstetrics \& Gynecology, Elblandklinikum, Riesa 01589, Germany; ${ }^{7}$ Department of Surgery, Athens University Medical School, Athens 11521, Greece; ${ }^{8}$ Department of Pathology, Western Infirmary, Glasgow G11 6NT, UK; ${ }^{9}$ Oncology Center, St Augustinus, Antwerp 2610, Belgium and ${ }^{10}$ Department of Medical Oncology, Erasmus MC-Daniel den Hoed Cancer Center, Rotterdam 3075EA, The Netherlands

Background: Epidermal growth factor receptors contribute to breast cancer relapse during endocrine therapy. Substitution of aromatase inhibitors (Als) may improve outcomes in HER-positive cancers.

Methods: Tissue microarrays were constructed. Quantitative analysis of HER1, HER2, and HER3 was performed. Data were analysed relative to disease-free survival and treatment using outcomes at 2.75 and 6.5 years.

Results: Among 4541 eligible samples, 4225 (93\%) had complete HER1-3 data. Overall, 5\% were HER1-positive, 13\% HER2positive, and 21\% HER3-positive; 32\% ( $n=1351)$ overexpressed at least one HER receptor. In the HER1-3-negative subgroup, the hazard ratio (HR) for upfront exemestane vs tamoxifen at 2.75 years was 0.67 ( $95 \%$ confidence interval (Cl), $0.52-0.87$ ), in the HER1-3-positive subgroup, the $\mathrm{HR}$ was $1.15(95 \% \mathrm{Cl}, 0.85-1.56)$. A prospectively planned treatment-by-marker analysis demonstrated a significant interaction between HER1-3 and treatment at 2.75 years $(\mathrm{HR}=0.58 ; 95 \% \mathrm{Cl}, 0.39-0.87 ; P=0.008)$, as confirmed by multivariate regression analysis adjusting for prognostic factors ( $\mathrm{HR}=0.55 ; 95 \% \mathrm{Cl}, 0.36-0.85 ; P=0.005)$. This effect was time dependent.

Conclusion: In the 2.75 years prior to switching patients initially treated with tamoxifen to exemestane, a significant treatmentby-marker effect exists between Al/tamoxifen treatment and HER1-3 expression, suggesting HER expression could be used to select appropriate endocrine treatment at diagnosis to prevent or delay early relapses.

Aromatase inhibitors (AIs) confer a disease-free survival (DFS) benefit over and above that achieved with adjuvant tamoxifen in postmenopausal women with early oestrogen-or progestronereceptor (ER/PgR)-positive breast cancer (Thurlimann et al,
2005; Forbes et al, 2008; van de Velde et al, 2011). Recent data from the Tamoxifen and Exemestane Adjuvant Multinational (TEAM) and Breast International Group (BIG) 1-98 trials suggest that DFS is similar in patients treated with either an AI for 5 years

*Correspondence: Professor JMS Bartlett; E-mail: John.Bartlett@oicr.on.ca

Previous publication: Portions of these data were presented by Dr Bartlett at the 31st, 32nd, and 33rd Annual SABCS Meetings in 2008 (abstract 81), 2009 (abstract 75), and 2010 (abstract S2-4), and the abstracts were published in Cancer Research supplements.

Received 25 June 2013; revised 3 September 2013; accepted 12 September 2013; published online 3 October 2013

(c) 2013 Cancer Research UK. All rights reserved 0007-0920/13 
or 'switched' to an AI following 2-3 years of tamoxifen (Thurlimann et al, 2005; van de Velde et al, 2011).

This observation has generated debate regarding the optimal treatment strategy (upfront AIs $v s$ switch) for postmenopausal ER/PgR-positive breast cancer. As, for all strategies, the benefit of AIs $v s$ tamoxifen is modest when compared with tamoxifen $v s$ no endocrine treatment (Abe et al, 2005; Viale et al, 2009), there is considerable impetus for translational studies aimed at identification of those patients most likely to benefit from upfront AIs.

The differences in benefit between hormonal regimens may be explained, in part, by the diverse biology of breast cancer, particularly the differences between luminal A and luminal B cancers (Perou et al, 2000). Clearly, multiple factors may influence differential response to hormonal treatments. Including HER2, Ki-67, and RAS/RAF or PI3K/Akt signalling (Beeram et al, 2007; Viale et al, 2008). Future selection of optimal endocrine therapy for early breast cancer will need to be personalised based on studies identifying an increasing number of patient subsets with unique molecular profiles, for example (Curtis et al, 2012).

Selecting optimal adjuvant endocrine therapy and/or chemotherapy is currently influenced by measures of residual risk (Van Belle et al, 2010). However, selection between endocrine agents (AIs $v s$ tamoxifen) requires specific markers indicating differential benefit from these agents. We have previously shown, within TEAM, that quantitative analysis of ER and PgR expression combined with clinicopathologic factors (age, tumour size and grade, and nodal status) can identify patients at higher risk for early recurrence (Bartlett et al, 2011). We confirmed previous data indicating that $\mathrm{PgR}$, although prognostic, is not a predictive marker of benefit from AI vs tamoxifen (Dowsett et al, 2008; Simon et al, 2009). Our study was, unlike previous studies, based on an adequately powered and prospectively planned treatmentby-marker analysis, satisfying criteria for high-level evidence (Simon et al, 2009).

Type 1 receptor kinase expression (HER1, HER2, and HER3 (HER1-3)) is associated with a higher probability of early relapse in tamoxifen-treated patients (Tovey et al, 2004, 2005), consistent with both preclinical and clinical data suggesting overexpression of HER2, and HER1/EGFR confer resistance to tamoxifen (Benz et al, 1992; Carlomagno et al, 1996; Houston et al, 1999). Conversely, neoadjuvant studies suggest that AIs are effective regardless of HER1 or HER2 overexpression (Ellis et al, 2001; Dixon et al, 2004). On the basis of these observations, we hypothesised that overexpression of HER1, HER2, and/or HER3 is associated with a differential benefit of an AI compared with tamoxifen in the adjuvant setting, and that outcome in patients with HER1-3positive tumours would be improved by initiating treatment with an AI rather than tamoxifen. The analysis presented here was prospectively planned and powered to test the hypothesis, within the TEAM study, that HER1-3 status acts as a predictive biomarker for benefit of exemestane $v s$ tamoxifen during the 2.75 years prior to the switch point.

\section{MATERIALS AND METHODS}

Study design. The TEAM trial, an international, open-label, phase III trial in postmenopausal women with ER/PgR-positive early breast cancer (van de Velde et al, 2011), included two prospectively planned and powered pathology studies. This, the second TEAM pathology study, tests the hypothesis that upfront exemestane improves DFS compared with tamoxifen in patients with HER1-3positive tumours, defined as tumours expressing high levels of at least one of HER1, HER2, or HER3 proteins. Outcomes in patients with high levels of HER1-3 expression were compared with those in patients without high HER1-3 expression. This intent-to-treat analysis was planned at 2.75 years follow-up and was not eventdriven (van de Velde et al, 2011). Using a two-sided $\alpha=0.05$ assuming a hazard ratio (HR) of 1.93 and HER1-3-positive prevalence of $25 \%$, a sample size of 4000 patients would give $>90 \%$ power to detect a treatment-biomarker interaction. Secondary exploratory analyses including DFS at 2.75 years, censoring patients at the actual time of switching, and DFS at a median follow-up of 6.5 years were performed.

Patients. Overall samples from 4781 patients were received from the United Kingdom (1097), The Netherlands (2722), Belgium (122), Germany (745) and Greece (95). Patient demographics and tumour characteristics were similar between the analysed subset and all patients in the pathology substudy; patients in the pathology subset were at slightly higher risk than the entire TEAM population (Bartlett et al, 2010) (Supplementary Table 1: CONSORT table).

In general, patients had histologically or cytologically confirmed T1-3 N0-2 M0 breast adenocarcinoma and were treated with surgical resection followed by radiotherapy and/or adjuvant chemotherapy. Among countries participating in the TEAM trial, five (United Kingdom/Ireland, The Netherlands, Belgium, Germany, and Greece) provided tumour samples for this substudy after appropriate ethical review.

Staining methodology. Tissue microarrays (TMAs) were constructed as reported previously (Bartlett et al, 2011), in line with current guidelines (Leyland-Jones et al, 2008). Standard immunohistochemical techniques were used to stain TMAs for HER1-3 (HER1 clone 31G7: Invitrogen, Paisley, UK; HER2, HercepTest, and HER3 clone DAK-H3-IC: Dako, Cambridgeshire, UK) and Ki67 (Clone MIB1, 1:50 dilution, Dako). Assays were performed to good laboratory practice (GLP) in a GLP-monitored laboratory using single batches of each antibody and reagent; incubations were rigorously controlled for temperature. In each assay, quality controls with varying HER expression were included as described previously for ER/PgR (Bartlett et al, 2011). Cores were scored manually for HER1-3 using highly trained observers (Kirkegaard et al, 2006). Histoscores for HER1-3 (membrane staining only) were recorded. For Ki67, scoring was performed using the Ariol SL-50 Image analysis system (Genetix, New Milton, UK) as previously described for ER/PgR (Bartlett et al, 2011) using an algorithm developed specifically for Ki67. Results for Ki67 were recorded as the percentage of Ki67 positive cells. HER2 status was confirmed by fluorescence in situ hybridisation (FISH) with 95\% concordance between immunohistochemical and FISH results (Wolff et al, 2007).

Statistical analysis. Disease-free survival, was defined as time from randomisation to earliest documentation of disease relapse (primary tumour recurrence (locoregional or distant) and ipsilateral/contralateral breast cancer) or death from any cause. The primary aim of this study was evaluation of the interaction between HER1-3 expression and treatment at 2.75 years on an intent-to-treat basis. Exploratory intent-to-treat analyses of interactions between HER1-3 expression and treatment were performed with 6.5 years median follow-up (van de Velde et al, 2011). A sensitivity analysis of the impact of censoring patients at the recorded time of treatment switch (Tam-AI) was performed. Exploratory analysis of DFS from 2.75 years postrandomization (excluding patients without follow-up after 2.75 years) until last recorded follow-up was performed. Data included in these analyses were locked on 1 February 2013.

The predictive value of HER expression was assessed using Cox proportional hazards regression models. Interactions between treatment arms and HER expression levels were evaluated using the Wald chi-square $\left(\chi^{2}\right)$ statistic. The predictive value of HER expression was further investigated in multivariate analyses, 
consistent with REMARK guidelines (McShane et al, 2006), adjusting for known prognostic factors: patient age (continuous variable); tumour size (continuous variable); number of positive nodes (continuous variable); treatment with chemotherapy (yes/no); treatment arm (tamoxifen/exemestane); and expression of HER1-3 (negative/positive), ER, PgR, and Ki67 (each a continuous variable). Continuous variables were evaluated for nonlinearity by applying simple log transformations followed by more complex fractional polynomials, and the best-fitting transformation was applied as assessed by the change in Akaike's information criterion between univariate Cox proportional hazard models of transformed and untransformed data (Collett, 1994). Treatment allocation was included as a time-dependent covariate to investigate the impact of switching on the tamoxifen randomised arm. The proportional hazards assumption was investigated and time and covariate interactions were analysed to evaluate changing effects with time. All data were analysed using SAS/STAT statistical software (SAS Institute, Cary, NC, USA).

\section{RESULTS}

Study population. Of 4541 eligible samples (Bartlett et al, 2011), 4225 (93\%) had complete HER1-3 data: 199 (5\%) were HER1positive; 547 (13\%) HER2-positive, and 875 (21\%) HER3-positive. Altogether, 1351 (32\%) tumours were positive for at least one HER1-3 biomarker. Patient demographics and tumour characteristics were similar between the analysed subset and all patients in the pathology substudy; patients in the pathology subset were at slightly higher risk $v s$ the entire TEAM population (Bartlett et al, 2010) (Supplementary Table 1: CONSORT table).
Efficacy

At 2.75 years, prospectively powered intent-to-treat analysis of treatment by HER1-3 marker expression. Among patients analysed in this substudy $(n=4225), 408$ DFS events were recorded over 2.75 years of follow-up. A trend towards DFS benefit of exemestane $v s$ tamoxifen $(\mathrm{HR}=0.84 ; 95 \%$ confidence interval (CI), 0.69-1.02) similar to the entire TEAM trial population was observed at 2.75 years (van de Velde et al, 2011). Among 2874 patients with HER1-3-negative tumours, 237 (8\%), and among the 1351 patients with HER1-3-positive tumours, 171 (13\%) DFS events occurred. HER1-3-positive patients had a $57 \%$ increased risk of a DFS event $v$ s HER1-3-negative patients $(\mathrm{HR}=1.57 ; 95 \% \mathrm{CI}: 1.29-1.91 ; P<0.0001)$. In the pre-planned treatment-by-marker analysis, there was a significant interaction between HER $1-3$ expression and treatment $(\mathrm{HR}=0.58$; 95\% CI, $0.39-0.87 ; \quad P=0.008)$ in favour of increased benefit from exemestane in HER1-3-negative patients (Figure 1A). Among HER1-3-negative patients, there was a DFS benefit associated with exemestane $v s$ tamoxifen $(\mathrm{HR}=0.67 ; 95 \%$ CI, 0.52-0.87; Figure 1B). Conversely, there was no marked treatment effect between exemestane and tamoxifen in HER1-3-positive patients $(\mathrm{HR}=1.15 ; 95 \% \mathrm{CI}, 0.85-1.56$; Figure 1C). In multivariate regression analysis, this treatment-by-marker interaction remained significant $(P=0.005 ; \mathrm{HR}=0.55 ; 95 \% \mathrm{CI}, 0.36-0.85)$, along with nodal status, tumour grade/size, patient age, ER, PgR, Ki67 (all as continuous variables); HER1-3 expression; and treatment (Table 1). Prior chemotherapy did not contribute significantly to risk at 2.75 years. Supplementary analysis at 2.75 years stratified by country shows similar interaction HRs across all countries (Table 2).
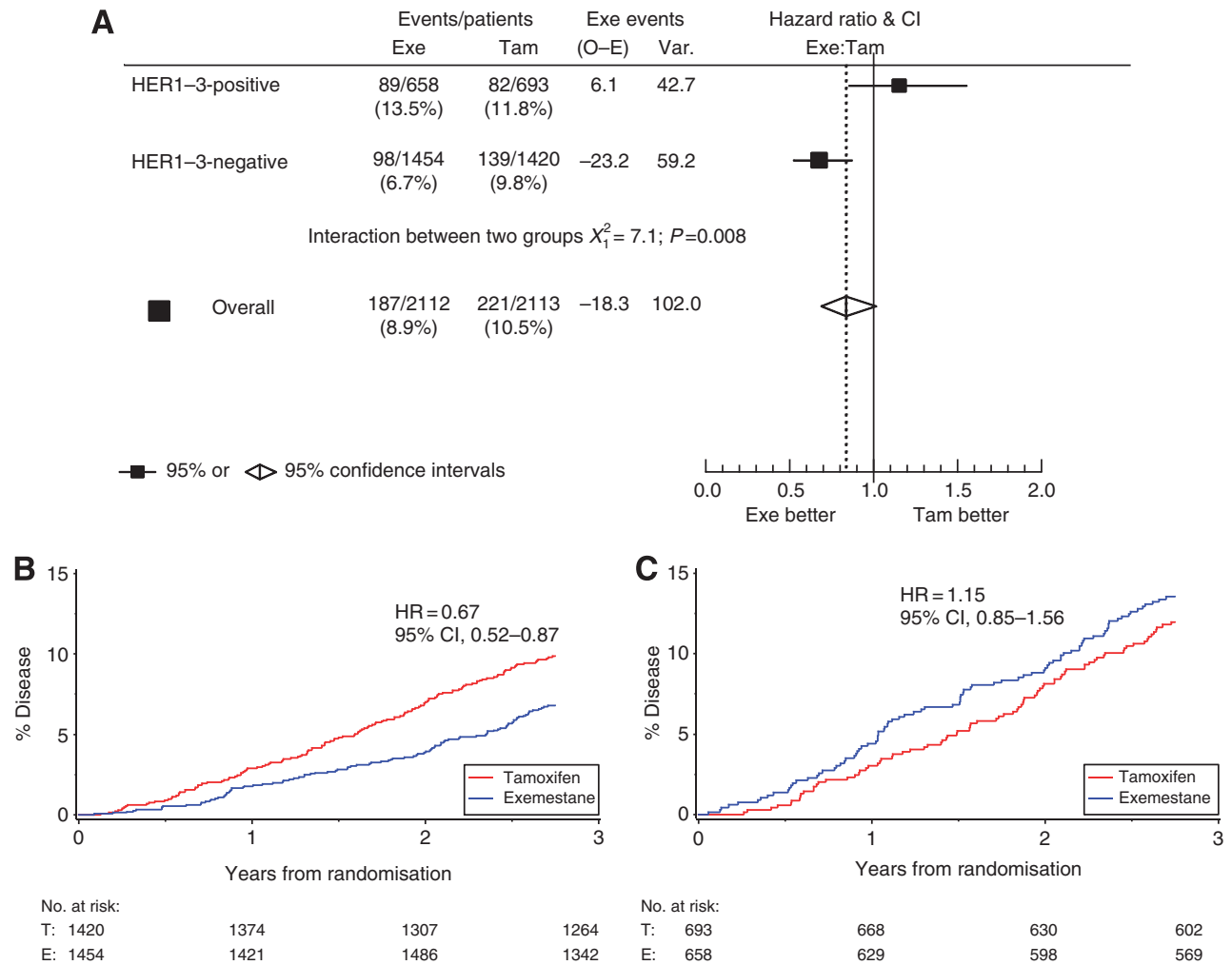

Figure 1. Disease-free survival in the intent-to-treat population at 2.75 years: (A) hazard ratio plot of treatment/biomarker interaction; (B) tumours negative for HER1, HER2, or HER3 ( $n=2874 ; 68 \%)$; and (C) tumours positive for HER1, HER2, or HER3 ( $n=1351 ; 32 \%)$. Abbreviations: $\mathrm{Cl}=$ confidence interval; $\mathrm{Exe}=$ exemestane; $\mathrm{HER}=$ human epidermal growth factor receptor; $\mathrm{HR}=$ hazard ratio; $\mathrm{O}-\mathrm{E}=$ observed minus expected; Tam = tamoxifen; $\operatorname{Var}=$ variance. 
Table 1. Multivariate analysis of disease-free survival at 2.75 years $(N=3779 ; 360$ DFS events)

\begin{tabular}{|c|c|c|c|}
\hline Variable & $\begin{array}{c}\text { Hazard ratio } \\
(95 \% \mathrm{Cl})\end{array}$ & $\begin{array}{c}\text { Wald } \\
\chi^{2}\end{array}$ & $\boldsymbol{P}$-value \\
\hline Age (per 10 years) & $1.35(1.20-1.52)$ & 26.0 & $<0.001$ \\
\hline ER (per 50 histoscore units) & $0.88(0.81-0.96)$ & 9.2 & 0.002 \\
\hline PgR (per 50 histoscore units) & $0.87(0.81-0.92)$ & 18.7 & $<0.001$ \\
\hline Ki67 (per 10\%) & $1.07(1.01-1.13)$ & 4.6 & 0.03 \\
\hline Tumour size ${ }^{a}$ & NA & 6.2 & 0.01 \\
\hline Number of positive nodes ${ }^{a}$ & NA & 50.6 & $<0.001$ \\
\hline $\begin{array}{l}\text { Second degree } \\
\text { transformation }(\wedge 2)\end{array}$ & NA & 18.4 & $<0.001$ \\
\hline
\end{tabular}

Tumour grade

\begin{tabular}{|l|c|c|c|}
\hline 1 & 1.00 & 6.7 & 0.04 \\
2 & $1.0(0.68-1.47)$ & & \\
\hline HER1-3 & $1.33(0.90-1.99)$ & & \\
\hline Treatment & $0.94(0.70-1.27)$ & 0.1 & 0.7 \\
\hline $\begin{array}{l}\text { HER1-3 treatment } \\
\text { interaction }\end{array}$ & $1.24(0.90-1.71)$ & 1.7 & 0.2 \\
\hline
\end{tabular}

Abbreviations: $\mathrm{Cl}=$ confidence interval; $\mathrm{ER}=$ oestrogen receptor; $\mathrm{HER}=$ human epidermal growth factor receptor; $\mathrm{PgR}=$ progesterone receptor; $\mathrm{NA}=$ not available.

${ }^{a}$ Nonlinear transformations for number of positive nodes $(\wedge 2)$, tumour size $(\wedge-0.5)$.

Prior chemotherapy $(\mathrm{Y} / \mathrm{N})$ was a nonsignificant variable excluded from the model. Units (see text) $\mathrm{Age}=$ years, $\mathrm{ER} / \mathrm{PgR}=$ histoscore $(0-300)$, and $\mathrm{Ki} 67=$ per cent positive cells. Hazard ratios for continuous variables (Age, ER/PgR, and Ki67) are expressed for an interval of 10 years (Age), 50 histoscore units (ER/PgR) or 10\% change in positivity (Ki67).

Table 2. Hazard ratios for the individual countries for HER1-3 expression and interaction with treatment arm

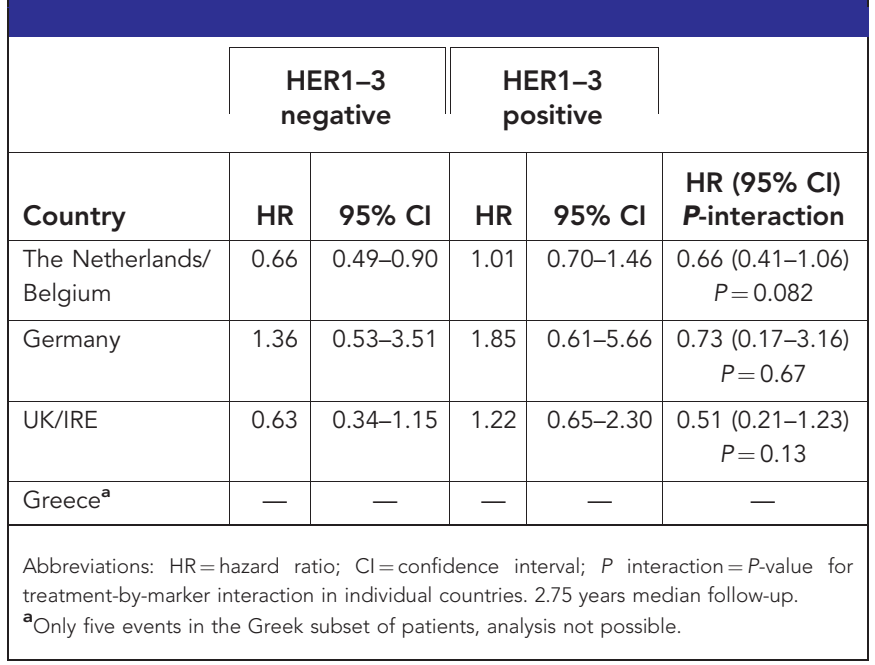

Exploratory analyses: HER1, HER2, and HER3 expression. Further exploratory analyses were performed for the individual HER receptors; benefit from upfront exemestane vs tamoxifen treatment was apparent in HER1-negative $(\mathrm{HR}=0.80 ; 95 \%$ $\mathrm{CI}, 0.65-0.98)$ vs HER1-positive tumours ( $\mathrm{HR}=1.60 ; 95 \% \mathrm{CI}$, $0.79-3.25$; interaction test $\mathrm{HR}=0.50 ; 95 \% \mathrm{CI}, 0.24-1.03 ; P=0.06$ ). Similarly, HER2-negative tumours indicated benefit from upfront exemestane vs tamoxifen ( $\mathrm{HR}=0.71 ; 95 \% \mathrm{CI}, 0.57-0.89)$, vs HER2-positive tumours ( $\mathrm{HR}=1.67$; 95\% CI, 1.09-2.55; interaction test $\mathrm{HR}=0.43 ; 95 \% \mathrm{CI}, 0.26-0.70 ; P<0.001)$. However, there was no apparent differential benefit among HER3-negative or
HER3-positive patients $(\mathrm{HR}=0.80 ; 95 \%$ CI, $0.64-0.99$ vs $\mathrm{HR}=1.00 ; 95 \% \mathrm{CI}, 0.65-1.53$; interaction test $\mathrm{HR}=0.80 ; 95 \%$ CI, $0.50-1.29 ; P=0.36$; Figure $2 \mathrm{~A}$ ). In a second exploratory analysis, tumours expressing either HER1 or HER2 were assumed (by the formation of active homo- or heterodimers) to exhibit 'active HER signalling', whereas tumours lacking HER1, HER2, and HER3 expression or expressing HER3 only were assumed to exhibit limited 'HER signalling' (Bartlett et al, 2010). A significant (exemestane vs tamoxifen) treatment-by-marker ('active HER signalling' $v s$ cases without 'active HER signalling') interaction $(\mathrm{HR}=0.42$; 95\% CI, 0.27-0.65; $P<0.001$; Figure $2 \mathrm{~B})$ suggests that patients with active HER signalling do not derive benefit from early exemestane treatment.

Exploratory 2.75-year censored analysis. The primary intent-totreat analysis (DFS at 2.75 years) evaluated benefit of exemestane and tamoxifen with relation to HER $1-3$ expression at the expected 'switch point' (tamoxifen patients switching to exemestane) of 2.75 years. However, 45\% (949/2113) of tamoxifen patients switched treatment before the 2.75-year follow-up, whereas 21\% (439/2113) discontinued tamoxifen early and did not switch. Among exemestane-treated patients, 12\% (257/2112) stopped treatment early. A sensitivity analysis censored all patients at the actual time of switch, at treatment cessation, or at 2.75 years, whichever occurred first. The time until treatment cessation (excluding those who switched) for patients who stopped treatment early was different in the two treatment arms (median treatment duration, 0.94 vs 0.67 years for tamoxifen-treated and exemestane-treated patients, respectively), leading to potential bias in this analysis. Among patients included in the sensitivity analysis $(n=4225), 278$ events were recorded. Comparing DFS at 2.75 years between HER1-3-negative and HER1-3-positive patients, as with the 2.75-year analysis, HER1-3-positive patients had significantly increased risk of a DFS event $(\mathrm{HR}=1.61 ; 95 \% \mathrm{CI}, 1.27-2.04$; $P<0.001)$. Analysis revealed that significant treatment-by-marker interaction between HER1-3 expression and treatment with exemestane/tamoxifen remained significant in both univariate $(\mathrm{HR}=0.50 ; 95 \% \mathrm{CI}, 0.31-0.81 ; P=0.0049$; Figure 3$)$, and multivariate analyses $(\mathrm{HR}=0.44 ; 95 \% \mathrm{CI}, 0.26-0.73 ; P=0.002)$.

Extended follow-up. In an unplanned analysis, data were also evaluated at a median follow-up of 6.5 years, including the period when all patients were treated with exemestane (unless they discontinued treatment). Among patients analysed $(n=4225)$, 1021 DFS events were recorded. No significant interaction between HER1-3 and treatment with tamoxifen $v s$ exemestane was observed $(\mathrm{HR}=1.05 ; 95 \% \mathrm{CI}, 0.82-1.36 ; \quad P=0.68)$. Among HER1-3-negative patients $(n=2874), 632$ (22\%) DFS events occurred, and among HER1-3-positive patients $(n=1351), 389$ (29\%) DFS events occurred (Figure 4A). There was no significant treatment effect (exemestane/tamoxifen) in HER1-3-positive patients $(\mathrm{HR}=0.93$; 95\% CI, 0.76-1.14; Figure 4B). In HER1-3negative patients, there was no longer a significant treatment effect between exemestane and tamoxifen ( $\mathrm{HR}=0.98$; 95\% CI, 0.84-1.15; Figure 4C). Relapses in the exemestane monotherapy group increased after the 2.75-year assessment and did not follow an extrapolation of the 2.75-year curve.

Analysis of treatment-by-marker interaction as a time-dependent covariate. By including each of the covariates as an interaction term with time in a Cox proportional hazard model, it is possible to investigate how the effect of each covariate on outcome varies with time. There is no significant interaction with time for either treatment or HER1-3 positivity. However, the hazard associated with the interaction between treatment and HER1-3 positivity significantly increases with time suggesting that HER1-3-negative patients treated with exemestane have an increased relapse risk as 


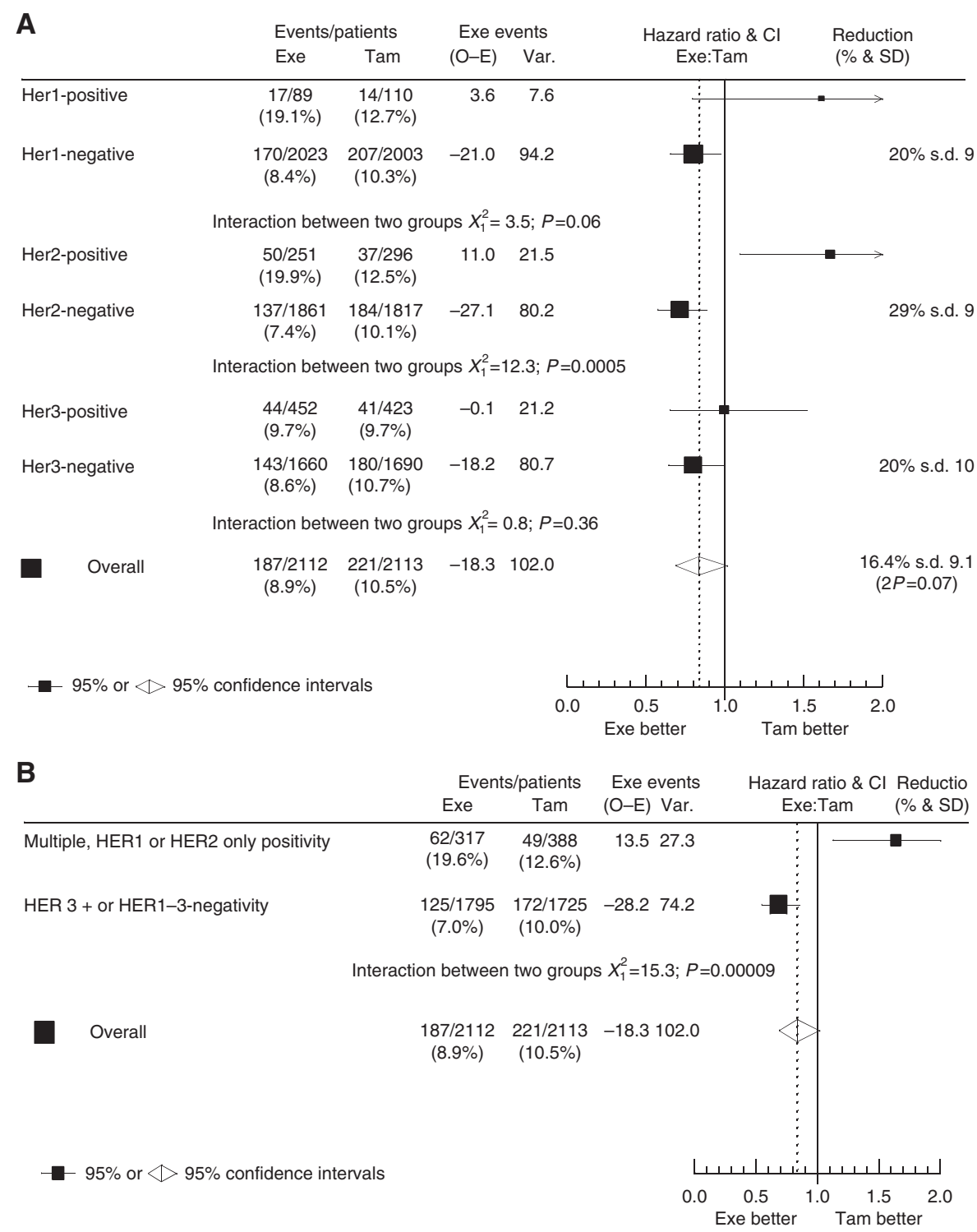

Figure 2. Contribution of each HER to disease-free survival benefit by treatment group: (A) interaction for individual HER receptors; and (B) activity of HER 'active' vs 'inactive' signalling. Abbreviations: $\mathrm{Cl}=$ confidence interval; Exe=exemestane; HER=human epidermal growth factor receptor; $\mathrm{HR}=$ hazard ratio; $\mathrm{O}-\mathrm{E}=$ observed minus expected; $\mathrm{Tam}=$ tamoxifen; $\mathrm{Var}=$ variance.

time progresses $(\mathrm{HR}=1.07,95 \%$ CI $1.01-1.14, P=0.017)$. Relapse risk increases by $7 \%$ per annum for HER1-3-negative exemestanetreated patients when compared with all other patients.

As expected, given the time dependence of the HER13/treatment interaction term, assessment of the proportional hazard assumptions of the Cox model shows that the hazard of disease is not proportional between the two groups (Figure 5). Relapse risks clearly diverge between $0-3$ years indicating that the hazard of disease during this time period for the two groups are not proportional. After 3 years, the proportionality assumptions are met. Therefore, the inclusion of the interaction with time of the treatment-by-marker interaction term is justified and explains the lack of evidence for treatment-by-marker interaction with extended follow-up without the use of a time-dependent model.

\section{DISCUSSION}

The results of this prospectively planned translational study show that expression of HER1, HER2, or HER3 predicts a differential benefit from initial adjuvant therapy with an AI compared with tamoxifen, which is shown to be both real and time dependent. In a prospectively planned and powered analysis, a significant DFS benefit in favour of initiating treatment with exemestane was observed among patients with HER1-3-negative tumours, in both univariate and multivariate analyses including the treatmentby-marker interaction (Figure 1, Table 1). Strikingly, this study did not show any benefit associated with initial exemestane treatment vs tamoxifen in patients with HER1-, HER2-, or HER3-positive tumours suggesting these tumours are partially resistant to endocrine therapy (Shou et al, 2004; Folgiero et al, 2008; Massarweh et al, 2008; Osborne et al, 2011). However, lack of overexpression of HER1, HER2, or HER3 is confirmed as an independent predictive biomarker for early AI benefit in patients with ER/PgR-positive early breast cancer. Exploratory analyses suggested that this effect was largely driven by HER1/HER2 expression, consistent with predicted HER signalling activity (HER3 lacks significant signalling potential) (Yarden and Pines, 2012). Therefore, assessing HER1/HER2 could provide valuable information in clinical practice in ER-positive disease (Hudelist et al, 2003; Sassen et al, 2008). Finally, in an exploratory 


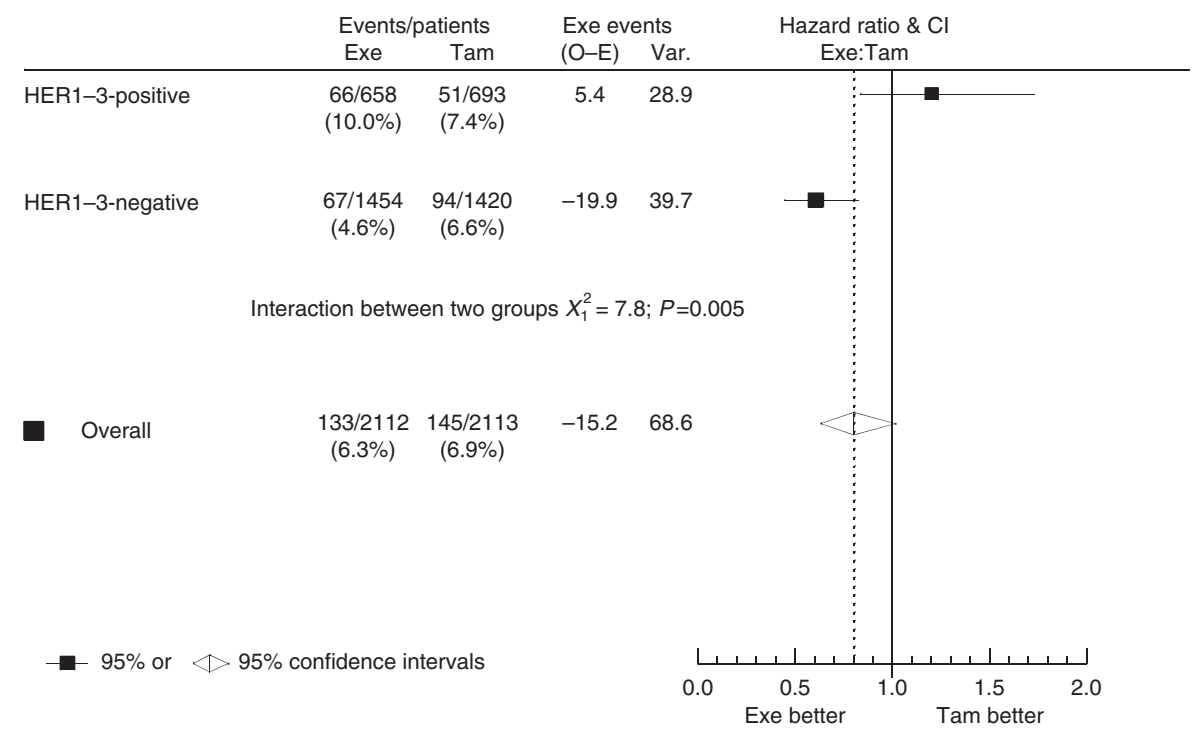

Figure 3. Hazard ratio plot of treatment-by-marker analysis, censoring patients at the time of treatment switch. This analysis presents diseasefree survival at 2.75 years; data in this figure are censored = whereas Figure $1 \mathrm{~A}$ data are not. Abbreviations: $\mathrm{Cl}=$ confidence interval; $\mathrm{Exe}=$ exemestane; $\mathrm{HER}=$ human epidermal growth factor receptor; $\mathrm{HR}=$ hazard ratio; $\mathrm{O}-\mathrm{E}=$ observed minus expected; Tam = tamoxifen; $\operatorname{Var}=$ variance

A

\begin{tabular}{|c|c|c|c|c|c|}
\hline & \multicolumn{2}{|c|}{ Events/patients } & \multicolumn{2}{|c|}{ Exe events } & \multirow{2}{*}{$\begin{array}{c}\text { Hazard ratio \& } \mathrm{Cl} \\
\text { Exe:Tam }\end{array}$} \\
\hline & Exe & Tam & $(\mathrm{O}-\mathrm{E})$ & Var. & \\
\hline HER1-3-positive & $\begin{array}{l}183 / 658 \\
(27.8 \%)\end{array}$ & $\begin{array}{l}206 / 693 \\
(29.7 \%)\end{array}$ & -6.8 & 97.2 & \\
\hline HER1-3-negative & $\begin{array}{c}320 / 1454 \\
(22.0 \%)\end{array}$ & $\begin{array}{c}312 / 1420 \\
(22.0 \%)\end{array}$ & -2.9 & 157.8 & \\
\hline \multicolumn{6}{|c|}{ Interaction between two groups $X_{1}^{2}=0.2 ; P=0.69$} \\
\hline Overall & $\begin{array}{c}503 / 2112 \\
(23.8 \%)\end{array}$ & $\begin{array}{c}518 / 2113 \\
(24.5 \%)\end{array}$ & -11.5 & 255.2 & $>$ \\
\hline
\end{tabular}
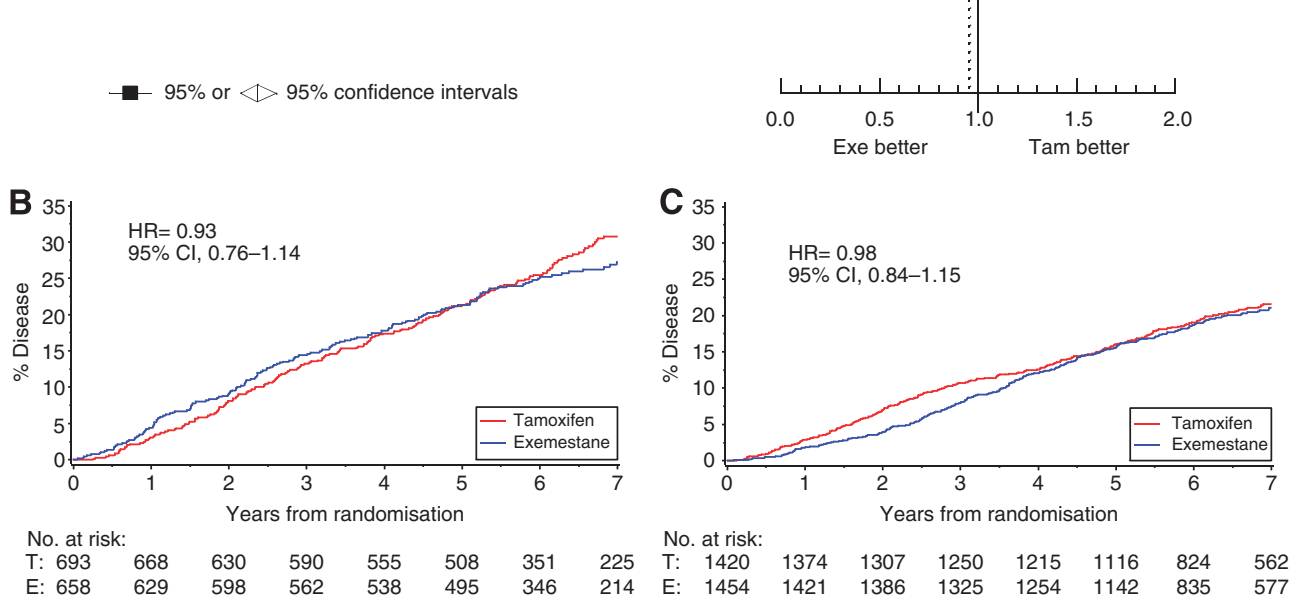

Figure 4. Disease-free survival in the intent-to-treat population at 5 years: (A) hazard ratio plot of treatment/biomarker interaction; (B) tumours positive for HER1, HER2, or HER3; and (C) tumours negative for HER1, HER2, or HER3. Abbreviations: $\mathrm{Cl}=$ confidence interval; Exe=exemestane; $\mathrm{HER}=$ human epidermal growth factor receptor; $\mathrm{HR}=$ hazard ratio; $\mathrm{O}-\mathrm{E}=$ observed to expected; $T$ am $=$ tamoxifen; $V$ ar $=$ variance.

time-dependent analysis (Figure 5), we identified a difference in the risk of relapse, relative to other tumours, associated with HER1-3-negative tumours treated with exemestane as time progressed. This time-dependent effect ultimately negates the treatment benefit observed in the pre-planned analysis (performed at 2.75 years) such that by 6.5 years median follow-up, no significant interaction between initial endocrine treatment and outcome is observed. Strikingly, in an exploratory analysis of DFS from treatment switch time point (2.75 years), the interaction term was inverted owing to the time-dependent effect in the HER1-3negative exemestane group (data not shown). Nonetheless the time-dependent analysis confirms the statistical robustness of the interaction during the initial treatment period prior to switching from tamoxifen to exemestane.

The lack of DFS benefit associated with exemestane in the HER1-3-positive subset observed in the current study is entirely 


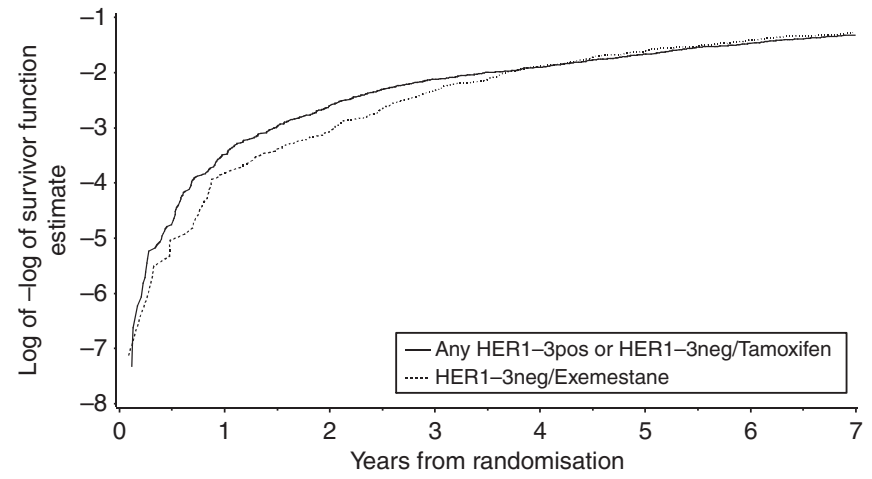

Figure 5. Log-log survivor plot for HER1-3-negative cases treated with exemestane (dashed line) vs all other cases (solid line).

Divergence of lines prior to 3-4 years postrandomisation is evidence of non-proportional hazard rates between groups at this time. After this time, the hazard of relapse appears to be proportional between groups.

consistent with data from transATAC (an ATAC substudy) indicating no difference between benefit from tamoxifen and anastrozole in HER2-positive cancers (Dowsett et al, 2008). In HER2-positive ATAC patients, recurrence rates were $18.8 \%$ among tamoxifen-treated patients vs 19.8\% among anastrozole-treated patients (Dowsett et al, 2008). Conversely, in HER2-negative patients, 5-year recurrence rates were $9.0 \%$ for tamoxifen-treated $v s$ $5.9 \%$ for anastrozole-treated patients (Dowsett et al, 2008). These data are consistent with a HER2 treatment-by-marker interaction HR of $\sim 0.6$, similar to that observed in the present study when patients received either tamoxifen or exemestane (prior to 2.75 years). In BIG-1-98, the possibility of a similar interaction between treatment and HER2 status is suggested by the fact that 48 fewer events were observed in the AI treatment arm for HER2-negative patients $v s 13$ more events in the AI-treated $v s$ tamoxifen-treated HER2-positive group (Viale et al, 2009). A future meta-analysis of this effect across multiple trials (in collaboration with the AI overview group) will be important in evaluating whether effects of HER2 signalling are consistent across multiple trials.

Another striking observation in the TEAM study is the time dependency of the interaction between HER1-3 and treatment (Figures 1 and 4). The subgroup of patients with HER1-3-negative tumours treated with exemestane experience a time-dependent increase in risk of disease relapse when compared with all other patients (Figure 5). This increase progressively erodes the benefit of early treatment with exemestane relative to tamoxifen in the HER1-3-negative group. This apparently paradoxical effect does not appear to occur in either the ATAC or BIG-1-98 studies. How then, could it be explained? The key difference between ATAC/ BIG-1-98 and TEAM is that the TEAM addresses specifically a switch from tamoxifen to AIs, whereas ATAC/BIG-1-98 predominantly address AIs vs 5 years of tamoxifen. Further analysis of the effect observed in the TEAM study could be performed in the relatively small switching arms within BIG-1-98. Exploration of a time-dependent effect of these different strategies is warranted; however, if such a time-dependent effect is not observed, the challenge of explaining our observations remains. We speculate that a proportion of HER1-3-negative early breast cancers are primed to develop endocrine resistance, as distinct from those with primary endocrine resistance, and that for a proportion of these cases AIs prevent or delay early recurrence. If our admittedly speculative hypothesis is correct, those cases where AIs delay recurrence may explain the increase in risk for HER1-3-negative patients observed in TEAM, while cases where switching from tamoxifen to AIs provides benefit may explain the convergence of the event rates for HER1-3-negative patients treated with tamoxifen followed by exemestane to those treated with AIs alone. Although we cannot speculate as to the molecular mechanisms relating to these trends, they reflect clinical experience with delayed recurrence following endocrine therapy.

Biomarker analyses raise questions relating to which biomarkers should be included in a risk assessment panel to achieve an optimal result, and how should data be interpreted? Overexpression of HER2 is associated with poor prognosis (Slamon et al, 1989), and the current analysis suggests that patients with HER1-3-positive tumours are at increased risk of early relapse regardless of treatment with exemestane $v s$ tamoxifen consistent with previous data that signalling through multiple members of the HER family is associated with endocrine resistance (Tovey et al, 2004, 2005; Naresh et al, 2006). In patients with HER1-3-negative tumours, the question becomes whether these patients benefit from upfront AI treatment rather than tamoxifen. Assessing signalling potential suggests that exemestane provides a significant differential DFS benefit $v$ s tamoxifen in tumours with 'inactive' HER1-3 signalling (Figure 3). These results suggest that the receptor activation may better indicate tumour response to adjuvant therapy than simple expression. The TEAM trial was conducted before introduction of adjuvant HER2-directed therapies, and for women eligible for HER2-directed therapy, an additional dimension exists in understanding the impact of such therapy.

In conclusion, upfront exemestane provided a superior DFS benefit compared with tamoxifen in tumours that were HER1-3negative or had inactive HER signalling. The time dependency of this effect was explained by a progressive increase in relapse risk, over time, in HER1-3-negative patients treated with exemestane. These results warrant further confirmation in meta-analyses. Tumours that are HER1-3-positive appear to be relatively resistant to endocrine therapy. Pragmatically in clinical practice, HER2 results should provide adequate information for selection of early endocrine therapy although the addition of HER1/EGFR results will be of benefit to a small proportion of patients.

\section{ACKNOWLEDGEMENTS}

We gratefully acknowledge the support of all pathologists, treating physicians, and the participation of all patients who consented to provide paraffin blocks for the study. Cassandra L Brookes was the lead statistician conducting analyses for the TEAM pathology substudy. Tammy Robson, Nicola Lyttle, and Mary Anne Quintayo were the highly trained observers who manually scored tissue cores. This study was conducted with the support of the Ontario Institute for Cancer Research through funding provided by the Government of Ontario. The TEAM trial is a multinational study supported by an unrestricted research grant by Pfizer Inc., and funding from Cancer Research UK (grant number C7602/A7215). Editorial support was provided by Tamara Fink, PhD, of Accuverus, a division of ProEd Communications, Inc., Beachwood, Ohio, and was funded by Pfizer Inc. Clinical trials registration numbers: NCT00036270, NCT00032136, NCT00279448, NTR 267, Ethics Commission Trial 27/2001, and UMIN C000000057.

\section{CONFLICT OF INTEREST}

Annette Hasenburg has received support for travel expenses to meetings for the study, payment for lectures (honoraria), and expert testimony from Pfizer. Dirk G Kieback has received speaker's honoraria and research grant funding from Pfizer. Christos Markopoulos has received speaker's honoraria and educational grants from AstraZeneca (UK), Novartis (Basel, Switzerland), Pfizer Inc. (New York, NY, USA) and Genomic 
Health Inc. (USA). Elizabeth A Mallon has received speaker's honoraria from Roche Pharmaceuticals. Daniel W Rea has received consultancy fees from Pfizer, Novartis, and Astra Zeneca. All remaining authors have declared no conflict of interest.

\section{REFERENCES}

Abe O, Abe R, Enomoto K, Kikuchi K, Koyama H, Masuda H, Nomura Y, Sakai K, Sugimachi K, Tominaga T, Uchino J, Yoshida M, Haybittle JL, Davies C, Harvey VJ, Holdaway TM, Kay RG, Mason BH, Forbes JF, Wilcken N, Gnant M, Jakesz R, Ploner M, Yosef HMA, Focan C, Lobelle JP, Peek U, Oates GD, Powell J, Durand M, Mauriac L, Di Leo A, Dolci S, Piccart MJ, Masood MB, Parker D, Price JJ, Hupperets PSGJ, Jackson S, Ragaz J, Berry D, Broadwater G, Cirrincione C, Muss H, Norton L, Weiss RB, Abu-Zahra HT, Portnoj SM, Baum M, Cuzick J, Houghton J, Riley D, Gordon NH, Davis HL, Beatrice A, Mihura J, Naja A, Lehingue Y, Romestaing P, Dubois JB, Delozier T, Mace-Lesec'h J, Rambert P, Andrysek O, Barkmanova J, Owen JR, Meier P, Howell A, Ribeiro GC, Swindell R, Alison R, Boreham J, Clarke M, Collins R, Darby S, Davies C, Elphinstone P, Evans V, Godwin J, Gray R, Harwood C, Hicks C, James S, MacKinnon E, McGale P, McHugh T, Mead G, Peto R, Wang Y, Albano J, de Oliveira CF, Gervasio H, Gordilho J, Johansen H, Mouridsen HT, Gelman RS, Harris JR, Henderson IC, Shapiro CL, Andersen KW, Axelsson CK, Blichert-Toft M, Moller S, Mouridsen HT, Overgaard J, Overgaard M, Rose C, Cartensen B, Palshof T, Trampisch HJ, Dalesio O, de Vries EGE, Rodenhuis S, van Tinteren H, Comis RL, Davidson NE, Gray R, Robert N, Sledge G, Tormey DC, Wood W, Cameron D, Chetty U, Forrest P, Jack W, Rossbach J, Klijn JGM, Treurniet-Donker AD, van Putten WLJ, Costa A, Veronesi U, Bartelink H, Duchateau L, Legrand C, Sylvester R, van der Hage JA, van de Velde CJH, Cunningham MP, Catalano R, Creech RH, Bonneterre J, Fargeot P, Fumoleau P, Kerbrat P, Namer M, Jonat W, Kaufmann M, Schumacher M, von Minckwitz G, Bastert G, Rauschecker H, Sauer R, Sauerbrei W, Schauer A, Schumacher M, de Schryver A, Vakaet L, Belfiglio M, Nicolucci A, Pellegrini F, Sacco M, Valentini M, McArdle CS, Smith DC, Galligioni E, Boccardo F, Rubagotti A, Dent DM, Gudgeon CA, Hacking A, Erazo A, Medina JY, Izuo M, Morishita Y, Takei H, Fentiman IS, Hayward JL, Rubens RD, Skilton D, Graeff H, Janicke F, Meisner C, Scheurlen H, Kaufmann M, von Fournier D, Dafni U, Fountzilas G, Klefstrom P, Blomqvist C, Saarto T, Margreiter R, Asselain B, Salmon RJ, Vilcoq JR, Arriagada R, Hill C, Laplanche A, Le MG, Spielmann M, Bruzzi P, Montanaro E, Rosso R, Sertoli MR, Venturini M, Amadori D, Benraadt J, Kooi M, van de Velde AO, Van Dongen JA, Vermorken JB, Castiglione M, Cavalli F, Coates A, Collins J, Forbes J, Gelber RD, Goldhirsch A, Lindtner J, Price KN, Rudenstam CM, Senn HJ, Bliss JM, Chilvers CED, Coombes RC, Hall E, Marty M, Borovik R, Brufman G, Hayat H, Robinson E, Wigler N, Bonadonna G, Camerini T, De Palo G, del Vecchio M, Formelli F, Valagussa P, Martoni A, Pannuti F, Cocconi G, Colozza A, Camisa R, Aogi K, Takashima S, Abe O, Ikeda T, Inokuchi K, Kikuchi K, Sawa K, Sonoo H, Korzeniowski S, Skolyszewski J, Ogawa M, Yamashita J, Bonte J (2005) Effects of chemotherapy and hormonal therapy for early breast cancer on recurrence and 15-year survival: an overview of the randomised trials. Lancet 365(9472): 1687-1717.

Bartlett JMS, Brookes CL, Robson T, van de Velde CJH, Billingham LJ, Campbell FM, Grant M, Hasenburg A, Hille ETM, Kay C, Kieback DG, Putter H, Markopoulos C, Kranenbarg EMK, Mallon EA, Dirix L, Seynaeve C, Rea D (2011) Estrogen receptor and progesterone receptor as predictive biomarkers of response to endocrine therapy: a prospectively powered pathology study in the Tamoxifen and Exemestane Adjuvant Multinational trial. J Clin Oncol 29(12): 1531-1538.

Bartlett JMS, Brookes CL, van de Velde CJH et al. (2010) Final results of a prospectively planned biomarker analysis: HER1-3 as predictive markers of benefit from early treatment with aromatase inhibitors versus tamoxifen in the TEAM pathology substudy. Cancer Res 70: 2-4.

Beeram M, Tan QTN, Tekmal RR, Russell D, Middleton A, DeGraffenried LA (2007) Akt-induced endocrine therapy resistance is reversed by inhibition of mTOR signaling. Ann Oncol 18(8): 1323-1328.

Benz CC, Scott GK, Sarup JC, Johnson RM, Tripathy D, Coronado E, Shepard HM, Osborne CK (1992) Estrogen-dependent, tamoxifen-resistant tumorigenic growth of Mcf-7 cells transfected with Her2/Neu. Breast Cancer Res Treat 24(2): 85-95.
Carlomagno C, Perrone F, Gallo C, Do LM, Lauria R, Morabito A, Pettinato G, Panico L, D'Antonio A, Bianco AR, De Placido S (1996) c-erbB2 overexpression decreases the benefit of adjuvant tamoxifen in early-stage breast cancer without axillary lymph node metastases. J Clin Oncol 14(10): 2702-2708.

Collett D (1994) Modelling Survival Data in Medical Research. Chapman \& Hall: London, UK.

Curtis C, Shah SP, Chin SF, Turashvili G, Rueda OM, Dunning MJ, Speed D, Lynch AG, Samarajiwa S, Yuan Y, Graf S, Ha G, Haffari G, Bashashati A, Russell R, McKinney S, Langerod A, Green A, Provenzano E, Wishart G, Pinder S, Watson P, Markowetz F, Murphy L, Ellis I, Purushotham A, Borresen-Dale AL, Brenton JD, Tavare S, Caldas C, Aparicio S (2012) The genomic and transcriptomic architecture of 2,000 breast tumours reveals novel subgroups. Nature 2012 486(7403): 346-352.

Dixon JM, Jackson J, Hills M, Renshaw L, Cameron DA, Anderson TJ, Miller WR, Dowsett M (2004) Anastrozole demonstrates clinical and biological effectiveness in oestrogen receptor-positive breast cancers, irrespective of the erbB2 status. Eur J Cancer 40(18): 2742-2747.

Dowsett M, Allred C, Knox J, Quinn E, Salter J, Wale C, Cuzick J, Houghton J, Williams N, Mallon E, Bishop H, Ellis I, Larsimont D, Sasano H, Carder P, Cussac AL, Knox F, Speirs V, Forbes J, Buzdar A (2008) Relationship between quantitative estrogen and progesterone receptor expression and human epidermal growth factor receptor 2 (HER-2) status with recurrence in the arimidex, tamoxifen, alone or in combination trial. J Clin Oncol 26(7): 1059-1065.

Ellis MJ, Coop A, Singh B, Mauriac L, Llombert-Cussac A, Janicke F, Miller WR, Evans DB, Dugan M, Brady C, Quebe-Fehling E, Borgs M (2001) Letrozole is more effective neoadjuvant endocrine therapy than tamoxifen for ErbB-1- and/or ErbB-2-positive, estrogen receptor-positive primary breast cancer: evidence from a phase III randomized trial. J Clin Oncol 19(18): 3808-3816.

Folgiero V, Avetrani P, Bon G, Di Carlo SE, Fabi A, Nistico C, Vici P, Melucci E, Buglioni S, Perracchio L, Sperduti I, Rosano L, Sacchi A, Mottolese M, Falcioni R (2008) Induction of ErbB-3 expression by alpha6beta4 integrin contributes to tamoxifen resistance in ERbeta1-negative breast carcinomas. PLoS One 3(2): e1592.

Forbes JF, Cuzick J, Buzdar A, Howell A, Tobias JS, Baum M (2008) Effect of anastrozole and tamoxifen as adjuvant treatment for early-stage breast cancer: 100-month analysis of the ATAC trial. Lancet Oncol 9(1): 45-53.

Houston SJ, Plunkett TA, Barnes DA, Smith P, Rubens RD, Miles DW (1999) Overexpression of c-erbB2 is an independent marker of resistance to endocrine therapy in advanced breast cancer. Br J Cancer 79(7-8): $1220-1226$.

Hudelist G, Singer CF, Manavi M, Pischinger K, Kubista E, Czerwenka K (2003) Co-expression of ErbB-family members in human breast cancer: Her-2/neu is the preferred dimerization candidate in nodal-positive tumors. Breast Cancer Res Treat 80(3): 353-361.

Kirkegaard T, Edwards J, Tovey S, McGlynn LM, Krishna SN, Mukherjee R, Tam L, Munro AF, Dunne B, Bartlett JMS (2006) Observer variation in immunohistochemical analysis of protein expression, time for a change? Histopathology 48(7): 787-794.

Leyland-Jones BR, Ambrosone CB, Bartlett J, Ellis MJC, Enos RA, Raji A, Pins MR, Zujewski JA, Hewitt SM, Forbes JF, Abramovitz M, Braga S, Cardoso F, Harbeck N, Denkert C, Jewell SD (2008) Recommendations for collection and handling of specimens from group breast cancer clinical trials. J Clin Oncol 26(34): 5638-5644.

Massarweh S, Osborne CK, Creighton CJ, Qin L, Tsimelzon A, Huang S, Weiss H, Rimawi M, Schiff R (2008) Tamoxifen resistance in breast tumors is driven by growth factor receptor signaling with repression of classic estrogen receptor genomic function. Cancer Res 68(3): 826-833.

McShane LM, Altman DG, Sauerbrei W, Taube SE, Gion M, Clark GM (2006) Reporting recommendations for tumor MARKer prognostic studies (REMARK). Breast Cancer Res Treat 100(2): 229-235.

Naresh A, Long WW, Vidal GA, Wimley WC, Marrero L, Sartor CI, Tovey S, Cooke TG, Bartlett JMS, Jones FE (2006) The ERBB4/HER4 intracellular domain $4 \mathrm{ICD}$ is a BH3-only protein promoting apoptosis of breast cancer cells. Cancer Res 66(12): 6412-6420.

Osborne CK, Neven P, Dirix LY, Mackey JR, Robert J, Underhill C, Schiff R, Gutierrez C, Migliaccio I, Anagnostou VK, Rimm DL, Magill P, Sellers M (2011) Gefitinib or Placebo in combination with tamoxifen in patients with hormone receptor-positive metastatic breast cancer: a randomized phase II study. Clin Cancer Res 17(5): 1147-1159. 
Perou CM, Sorlie T, Eisen MB, Van de Rijn M, Jeffrey SS, Rees CA, Pollack JR, Ross DT, Johnsen H, Akslen LA, Fluge O, Pergamenschikov A, Williams C, Zhu SX, Lonning PE, Borresen-Dale AL, Brown PO, Botstein D (2000) Molecular portraits of human breast tumours. Nature 406(6797): 747-752.

Sassen A, Rochon J, Wild P, Hartmann A, Hofstaedter F, Schwarz S, Brockhoff G (2008) Cytogenetic analysis of HER1/EGFR, HER2, HER3 and HER4 in 278 breast cancer patients. Breast Cancer Res 10(1): R2.

Shou J, Massarweh S, Osborne CK, Wakeling AE, Ali S, Weiss H, Schiff R (2004) Mechanisms of tamoxifen resistance: increased estrogen receptorHER2/neu cross-talk in ER/HER2-positive breast cancer. J Natl Cancer Inst 96(12): 926-935.

Simon RM, Paik S, Hayes DF (2009) Use of archived specimens in evaluation of prognostic and predictive biomarkers. J Natl Cancer Inst 101(21): 1446-1452.

Slamon DJ, Godolphin W, Jones LA, Holt JA, Wong SG, Keith DE, Levin WJ, Stuart SG, Udove J, Ullrich A, Press MF (1989) Studies of the HER-2/neu proto-oncogene in human breast and ovarian cancer. Science 244(4905): 707-712.

Thurlimann B, Keshaviah A, Coates AS, Mouridsen H, Mauriac L, Forbes JF, Paridaens R, Castiglione-Gertsch M, Gelber RD, Rabaglio M, Smith I, Wardley A, Price KN, Goldhirsch A (2005) A comparison of letrozole and tamoxifen in postmenopausal women with early breast cancer. N Engl J Med 353(26): 2747-2757.

Tovey SM, Dunne B, Witton CJ, Forsyth A, Cooke TG, Bartlett JMS (2005) Can molecular markers predict when to implement treatment with aromatase inhibitors in invasive breast cancer? Clin Cancer Res 11(13): 4835-4842.

Tovey SM, Witton CJ, Bartlett JMS, Stanton PD, Reeves JR, Cooke TG (2004) Outcome and human epidermal growth factor receptor (HER) 1-4 status in invasive breast carcinomas with proliferation indices evaluated by bromodeoxyuridine labelling. Breast Cancer Res 6(3): R246-R251.

Van Belle V, Van Calster B, Brouckaert O, Vanden Bempt I, Pintens S, Harvey V, Murray P, Naume B, Wiedswang G, Paridaens R, Moerman P, Amant F, Leunen K, Smeets A, Drijkoningen M, Wildiers H, Christiaens MR, Vergote I, Van Huffel S, Neven P (2010) Qualitative assessment of the progesterone receptor and HER2 improves the Nottingham Prognostic Index up to 5 years after breast cancer diagnosis. J Clin Oncol 28(27): 4129-4134. van de Velde CJH, Rea D, Seynaeve C, Putter H, Hasenburg A, Vannetzel JM, Paridaens R, Markopoulos C, Hozumi Y, Hille ETM, Kieback DG, Asmar L, Smeets J, Nortier JWR, Hadji P, Bartlett JMS, Jones SE (2011) Adjuvant tamoxifen and exemestane in early breast cancer (TEAM): a randomised phase 3 trial. Lancet 377(9762): 321-331.

Viale G, Giobbie-Hurder A, Regan MM, Coates AS, Mastropasqua MG, Dell'Orto P, Maiorano E, MacGrogan G, Braye SG, Ohlschlegel C, Neven P, Orosz Z, Olszewski WP, Knox F, Thurlimann B, Price KN, Castiglione-Gertsch M, Gelber RD, Gusterson BA, Goldhirsch A (2008) Prognostic and predictive value of centrally reviewed Ki-67 labeling index in postmenopausal women with endocrine-responsive breast cancer: results from Breast International Group Trial 1-98 comparing adjuvant tamoxifen with letrozole. J Clin Oncol 26(34): 5569-5575.

Viale G, Regan MM, Dell'Orto P, Mastropasqua MG, Rasmussen BB, MacGrogan G, Braye S, Orosz Z, Giobbie-Hurder A, Neven P, Knox F, Oehlschlegel C, Thuerlimann B, Coates AS, Goldhirsch A (2009) Central review of ER, PgR and HER2 in BIG 1-98 evaluating letrozole vs. letrozole followed by tamoxifen vs. tamoxifen followed by letrozole as adjuvant endocrine therapy for postmenopausal women with hormone receptorpositive breast cancer. Cancer Res 69(24): 504S.

Wolff AC, Hammond ME, Schwartz JN, Hagerty KL, Allred DC, Cote RJ, Dowsett M, Fitzgibbons PL, Hanna WM, Langer A, McShane LM, Paik S, Pegram MD, Perez EA, Press MF, Rhodes A, Sturgeon C, Taube SE, Tubbs R, Vance GH, van de Vijver M, Wheeler TM, Hayes DF (2007) American Society of Clinical Oncology/College of American Pathologists guideline recommendations for human epidermal growth factor receptor 2 testing in breast cancer. J Clin Oncol 25(1): 118-145.

Yarden Y, Pines G (2012) The ERBB network: at last, cancer therapy meets systems biology. Nat Rev Cancer 12(8): 553-563.

This work is published under the standard license to publish agreement. After 12 months the work will become freely available and the license terms will switch to a Creative Commons AttributionNonCommercial-Share Alike 3.0 Unported License.

Supplementary Information accompanies this paper on British Journal of Cancer website (http://www.nature.com/bjc) 